\title{
DAMAGING EFFECT OF IMMOBILIZING STRESS ON HYPOXIA HIGH- AND LOW-RESISTANT RATS OF BOTH SEXES
}

\author{
Iu. M. Ordynskyi, O. V. Denefil \\ I. HORBACHEVSKY TERNOPIL STATE MEDICAL UNIVERSITY, TERNOPIL, UKRAINE
}

Background. Cardiovascular morbidity is a topical issue; stress is an essential contributing factor. Pathogenic links in damaging stress impact on the animal units of different reactivity is promising in disease prevention and development of individual correction methods.

Objective. Stress-induced development of cardiovascular pathology is undeniable, the stress impact depending on individual systemic response, age and sex.

Methods. 96 hypoxia high- and low-resistant (HR and LR, respectively) Wistar rats aged 5.5-6 months were used in experiments. Changes of lipid peroxidation processes, as well as protein oxidative modification, nitrite anion content and the indices of antioxidant defence under immobilizing stress were studied in the research.

Results. Immobilizing stress causes the development of oxidative and carbonyl stress in HR and LR rats that is more pronounced in LR group; and the activation of antioxidant defence system. In males, stress development is concomitant with increased catalase activity as well as that of blood peroxidase, ceruloplasmin and reduced glutathione content, whereas increased catalase and ceruloplasmin activity has been found in HR females, and that of superoxide dismutase and ceruloplasmin - in LR group. As compared with the females, more intensive oxidative and nitroxidative stress, protein oxidative modification, and stress-related accumulation of circulating immune complexes have been found in the males.

Conclusions. The most intensive oxidative and nitroxidative stress, protein oxidative modification, and stress-related accumulation of circulating immune complexes have been found in the hypoxia low-resistant males.

KEY WORDS: immobilizing stress, resistance to hypoxia, heart, damage.

\section{Introduction}

Stresses are common in daily life and work [1], the long-lasting ones being the most dangerous. The same stressor impacts the people of various sex and age differently [2], the aftermath depends on a person's reactivity, nervous and endocrine regulation, immune system, resistance to surroundings, etc. Cardiovascular morbidity is a topical issue; stress is an essential contributing factor [3]. Pathogenic links in damaging stress impact on the animal units of different reactivity is promising in disease prevention and development of individual correction methods.

Therefore, the research was aimed to determine the lipid peroxidation changes, nitrite anion and protein oxidative modification products content as well as of the antioxidant defence in heart of stress-exposed HR and LR rats of both sexes.

Corresponding author: Olha Denefil, Department of Pathological Physiology, I. Horbachevsky Ternopil State Medical University, 1 Maidan Voli, Ternopil, Ukraine, 46001

Phone number: +380352431262

E-mail:denefil@tdmu.edu.ua

\section{Material and Methods}

96 hypoxia high- and low-resistant (HR and LR, respectively) Wistar rats aged 5.5-6 months were used in the research. The animals were divided into groups: control and experimental (exposed to chronic stress), each group comprising 12 males and 12 females. Animal units with different resistance to hypoxia were separated in accordance with V. Ya. Berezovskiy method (1978) [4]. Stress was simulated by immobilization of the rats in supine position (1 hour/4 times, stress episodes at 72-hour interval). 24 hours after the $4^{\text {th }}$ fixation the animals were withdrawn from the procedure [5].

Experiments were performed in a special room within the morning at $18-22{ }^{\circ} \mathrm{C}$, relative humidity $40-60 \%$ and illumination 250 lux. The regulations of the European Convention for the Protection of Vertebrate Animals used for Experimental and other Scientific Purposes (Strasbourg, 18.03.1986), Resolution of the I National Congress on Bioethics (Kyiv, 2001) and the order of the Ministry of Health of Ukraine № 690 of 23.09.2009, were strictly followed. 
The rats were euthanized by total heart bloodletting and previous thiopental sodium anaesthesia (60 mg. $\mathrm{g}^{-1}$ b.w. intraperitoneally). Blood and heart samples were taken for the research. Concentration of diene conjugates (DC), triene conjugates (TC), Schiff bases [6], TBA-active products [7]; indices of protein oxidative modification (POM 370 and POM 430) [8], nitrite anion [9], circulating immune complexes (CIC) [10], superoxide dismutase (SDA) [11], catalase [12] activity, and ceruloplasmin (CP) content [13] were determined in heart homogenate, whereas peroxidase blood activity (PBA) [14], reduced glutathione (RGI) [15], as well as glutathione peroxidase and glutathione reductase activity[16] were determined in blood serum.

Statistical analyses of digital data was performed by Department of Systemic Statistical Research of the University by means of Excel (Microsoft, USA) and STATISTICA 6.0 (Statsoft, USA). Reliability of the value difference between independent quantities was determined by Student t-test at normal distribution and by nonparametric methods in other cases.

\section{Results and Discussion}

lower lipid peroxidation activity was revealed in the control HR males as compared with the LR animals, that was confirmed by $6.78 \%$ lower $(p<0.001)$ indices of TBA-active products (Table 1).
Under chronic stress, the significant increase of primary and intermediate lipid peroxidation products: DC - in 2.26 times $(p<0.001)$, TC - in 3.56 times $(p<0.001)$, TBAactive products - in 4.45 times $(p<0.001)$, whereas Schiff bases decreased by $32.32 \%$ $(p<0.001)$ was revealed the HR group. In the LR group the $D C$ value increased in 5.99 times $(p<0.001)$, TC - in 6.80 times $(p<0.001)$, TBAactive products - in 5.81 times $(p<0.001)$, and Schiff bases decreased by $22.84 \%(p<0.001)$. As compared with the LR group, the HR group presented lower lipid peroxidation values: $D C$ - in 2.73 times $(p<0.001), T C-$ in 1.99 times $(p<0.001)$, TBA-active products - in 1.39 times $(p<0.001)$, and Schiffbases - by $9.35 \%(p<0.001)$. This data evidenced progressing oxidative and carbonyl stress in the HR and LR male rats that was more pronounced in the last group.

As compared with LR group, higher activity of primary and final lipid peroxidation products (DC - by $14.38 \%, p<0.001$, Schiff bases - by $31.12 \%, p<0.001)$ and lower concentration of TBA-active products (by $8.01 \%, \mathrm{p}<0.001$ ) were revealed in the control HR females. The data proved more intensive lipid peroxidation process in the intact HR females, probably due to more potent activity of antioxidant and endocrine system. The former is confirmed by the fact that in HR females TC values were by $14.67 \%(p<0.001)$ higher and Schiff bases values - by $22.12 \%$ $(p<0.001)$ lower as compared with the HR males.

Table 1. Stress-related changes of lipid peroxidation indices in HR and LR animals of both sexes $M \pm m(n=12)$

\begin{tabular}{|c|c|c|c|c|}
\hline \multirow[b]{2}{*}{ Group } & \multicolumn{4}{|c|}{ Index } \\
\hline & $\begin{array}{l}\text { Diene conjugates, } \\
\text { standard unit. g. }{ }^{-1}\end{array}$ & $\begin{array}{l}\text { Triene conjugates } \\
\text { standard unit. g. }{ }^{-1}\end{array}$ & $\begin{array}{c}\text { TBA-a active } \\
\text { products } \mathrm{mcmol} / \mathrm{kg}\end{array}$ & $\begin{array}{l}\text { Schiff bases } \\
\text { standard unit }\end{array}$ \\
\hline \multicolumn{5}{|c|}{ Males } \\
\hline \multicolumn{5}{|c|}{$\mathrm{HR}$} \\
\hline Control & $0.975 \pm 0.021$ & $0.994 \pm 0.013$ & $0.906 \pm 0.012$ & $1.413 \pm 0.100$ \\
\hline Stress & $2.209 \pm 0.057 *$ & $3.537 \pm 0.103 *$ & $3.537 \pm 0.103 *$ & $0.956 \pm 0.009 *$ \\
\hline \multicolumn{5}{|c|}{ LR } \\
\hline Control & $1.005 \pm 0.010$ & $0.994 \pm 0.013$ & $0.967 \pm 0.006 * *$ & $1.354 \pm 0.055$ \\
\hline Stress & $6.025 \pm 0.794 * * \star *$ & 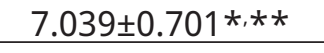 & $5.625 \pm 0.163 *$ ** & $1.044 \pm 0.019 *, * *$ \\
\hline \multicolumn{5}{|c|}{ Females } \\
\hline \multicolumn{5}{|c|}{$\mathrm{HR}$} \\
\hline Control & $0.952 \pm 0.024$ & $1.140 \pm 0.032^{\#}$ & $0.899 \pm 0.002$ & $1.100 \pm 0.016^{\#}$ \\
\hline Stress & $1.023 \pm 0.001$ *,\# & $0.972 \pm 0.005^{*, \#}$ & $1.319 \pm 0.008^{*, \#}$ & $1.043 \pm 0.006 *, \#$ \\
\hline \multicolumn{5}{|c|}{ LR } \\
\hline Control & $0.861 \pm 0.006 * *, \#$ & $0.966 \pm 0.017^{\#}$ & $0.971 \pm 0.005 * *$ & $0.932 \pm 0.016^{* *, \#}$ \\
\hline Stress & $1.027 \pm 0.013^{*, \#}$ & $1.074 \pm 0.006 *, \star *, \#$ & $1.865 \pm 0.014 *, * *, \#$ & $1.038 \pm 0.003 *$ \\
\hline \multicolumn{5}{|c|}{$\begin{array}{l}\text { Notes: }{ }^{*}-\text { reliable indices as compared with the controls; } \\
* *-\text { reliable indices as compared with the } \mathrm{HR} \\
*-\text { reliable indices as compared with the males of corresponding group. }\end{array}$} \\
\hline IS & 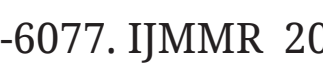 & . & & dynsh \\
\hline
\end{tabular}


As compared with the HR females, TC indices lower by $14.67 \%(p<0.001)$ and Schiff bases values higher by $22.12 \%(p<0.001)$ were revealed in the control HR males. In comparison with the LR females, DC indices higher by $14.38 \%(p<0.001)$ were revealed in the LR males, whereas TC and Schiff bases values were by $6.63 \%(p<0.002)$ and $31.12 \%(p<0.001)$ higher, respectively. These findings indicated more intensive lipid peroxidation process in females alongside with potent activity of antioxidant system that provided neutralization of lipid peroxidation products through decreased Schiff bases' production. More intensive lipid peroxidation course under stress was revealed in the males. As compared with HR females, the increase in DC in 2.16 times $(p<0.001)$ was revealed in the HR males, whereas TC increased in 3.64 times $(p<0.001)$, TBA-active products - in 3.06 times $(p<0.001)$, and Schiff bases - by $9.06 \%$ $(p<0.001)$. In comparison with the LR females the increase in $D C$ in 5.86 times $(p<0.001)$ was evidenced in the LR males, whereas TC increased in 6.56 times $(p<0.001)$, and TBA-active products in 3.01 times $(p<0.001)$. Thus, stress impact is responsible for more intensive lipid peroxidation course in males that can be attributed to activated sympathetic division of autonomic nervous system, as well as to the less potent or more intensive antioxidant discharge, and to the decrease of sex hormones protective effect.
The study of protein oxidative modification revealed reduced POM 370 and POM 430 values in the control HR males as compared with the LR group (by $7.23 \%, p<0.001$ and by $10.11 \%$, $\mathrm{p}<0.001$, respectively, table 2 ). Under stress impact, POM 370 decreased by $11.64 \%, p<0.001$ in the HR group, while POM 430 increased by $65.69 \%, p<0.001$. The POM 370 index decreased in the LR group by $24.32 \%, p<0.001$; POM 370 and POM 430 values were higher in the HR group (by $8.17 \%, p<0.001$ and by $26.63 \%$, $\mathrm{p}<0.001$, respectively).

As against the LR group, higher POM 370 (by $13.57 \%, p<0.001$ ) was revealed in the control HR females. Under stress impact, the decreased POM 370 (by $13.07 \%, p<0.001$ ) and increased POM 430 (by $69.19 \%, p<0.001$ ) were revealed in the HR group, whereas in the LR group POM 370 decreased by $23.59 \%$, $p<0.001$, but POM 430 decreased by $46.39 \%, p<0.001$. POM 370 and POM 430 were higher in the HR group (by $24.02 \%, p<0.001$ and $16.14 \%, p<0.001$, respectively).

As compared with the females, higher POM 370 and POM 430 indices (in the HR - by $11.57 \%$, $p<0.001$ and by $15.41 \%, p<0.001$; in the LR - by $28.72 \%, p<0.001$ and by $25.59 \%, p<0.001$, respectively) were revealed in the control males. Under stress impact, higher POM 370 and POM 430 indices were revealed in the HR males in comparison with the females (by

Table 2. Stress-related changes in the indices of protein oxidative modification nitric oxide anion-radical, and circulating immune complexes (CIC) in HR and LR rats of both sexes, $\mathrm{M} \pm \mathrm{m}(\mathrm{n}=12)$

\begin{tabular}{|l|c|c|c|c|}
\hline \multirow{3}{*}{ Group } & $\begin{array}{c}\text { POM 370, } \\
\text { mmol/g of protein }\end{array}$ & $\begin{array}{c}\text { POM 430, } \\
\mathrm{mmol} / \mathrm{g} \text { of protein }\end{array}$ & $\begin{array}{c}\text { Nitrite anion, } \\
\mathrm{x} 10^{-3}, \mathrm{mkmol} / \mathrm{l}\end{array}$ & $\begin{array}{c}\text { CIC, standard } \\
\text { unit }\end{array}$ \\
\cline { 2 - 5 } & \multicolumn{5}{|c|}{ Males } \\
\hline \multicolumn{5}{|c|}{ HR } \\
\hline Control & $1175.08 \pm 3.71$ & $712.69 \pm 11.09$ & $1.044 \pm 0.075$ & $57.66 \pm 1.67$ \\
\hline Stress & $1038.32 \pm 7.84^{*}$ & $1180.86 \pm 4.74^{*}$ & $9.564 \pm 0.301^{*}$ & $118.00 \pm 3.85^{*}$ \\
\hline \multicolumn{5}{|c|}{ LR } \\
\hline Control & $1260.00 \pm 3.51^{* *}$ & $784.74 \pm 3.80^{* *}$ & $1.189 \pm 0.083$ & $56.25 \pm 0.84$ \\
\hline Stress & $953.53 \pm 38.05^{*, * *}$ & $866.38 \pm 53.34^{* *}$ & $5.410 \pm 0.124^{*, * *}$ & $103.25 \pm 1.63^{*, * *}$ \\
\hline \multicolumn{5}{|c|}{ Females } \\
\hline Control & $1039.11 \pm 17.20^{\# \#}$ & $602.83 \pm 13.05^{\# \#}$ & $0.988 \pm 0.059$ & $54.00 \pm 1.41$ \\
\hline Stress & $903.26 \pm 8.45^{*, \# \#}$ & $1019.42 \pm 20.91^{*, \# \#}$ & $1.792 \pm 0.048^{*, \# \#}$ & $86.00 \pm 1.33^{*, \# \#}$ \\
\hline \multicolumn{5}{|c|}{$\mathrm{LR}$} \\
\hline Control & $898.14 \pm 35.92^{* *, \# \#}$ & $583.93 \pm 11.77^{\# \#}$ & $1.156 \pm 0.039^{* *}$ & $50.00 \pm 0.77^{* *, \# \#}$ \\
\hline Stress & $686.31 \pm 13.02^{*, * *, \# \#}$ & $854.83 \pm 14.20^{*, * *}$ & $1.876 \pm 0.038^{*, \# \#}$ & $83.50 \pm 1.66^{*, \# \#}$ \\
\hline
\end{tabular}

Notes: * -reliable indices as compared with the controls;

** - reliable indices as compared with the HR;

\#\# - reliable indices as compared with the males of corresponding group. 
$13.01 \%, p<0.001$ and by $13.67 \%, p<0.001$, respectively), whereas in the LR males POM 370 index was higher by $28.025 \%, p<0.001$.

Thus, decreasing POM 370 index was revealed in all groups due to the stress effect, whereas POM 430 increased in all HR rats and LR females, indicating the development of oxidative stress, and is likely to be related to free-radical oxidation of lipids which act on the proteins as potent oxidizers.

No reliable difference in nitrite anion values between the control HR and LR males was found. Under stress impact, the index increased in the HR group in 9.2 times, $p<0.001$, and in the LR group - in 4.5 times, $p<0.001$ that was higher by $43.43 \%, p<0.001$ in the HR group. The values of nitrite anion of the control HR females were by $16.95 \%, p<0.005$ lower as compared with the LR group. Under stress, the value increased in 43.84 times, $p<0.001$ in the HR group and in 32.66 times, $p<0.001$ - in the LR group. No significant difference in nitrite anion values as against the females was revealed in the control males. Under stress, the values of the females increased as compared to the males (in the HR group - by $81.26 \%, p<0.001$, in the LR group - by $65.32 \%$, $p<0.001$ ).

Thus, in comparison with the males, more intensive nitrite anion accumulation has been found in the females that may evidence the development of active oxygen forms in the females.
As against the LR group, CIC values in the control HR males were similar. Under stress, they increased in the HR group in 2.0 times $(p<0.001)$ and in the LR group - in 1.8 times $(p<0.001)$ that was by $12.50 \%(p<0.001)$ lower in the LR group. In the control HR females the CIC value was $7.41 \%(p<0.001)$ higher as compared with the LR group. Under stress, the value increased in 2.90 times $(p<0.001)$ in the HR group and in 3.29 times $(p<0.001)$ in the LR group that was higher in the latter by $5.16 \%$ $(p<0.001)$.

As compared with the females, the CIC value was by $11.11 \%(p<0.001)$ higher in the control LR males. Under stress, the CIC values were by $27.12 \%(p<0.001)$ higher in the HR males as compared with the females, and in the LR group - by $19.13 \%(p<0.001)$ higher.

The research findings proved more significant CIC increase in the males as compared with the females, and in the HR males against the LR males. The CIC increase is fraught with the development of autoimmune diseases.

The study of antioxidant defence enzymatic link (Table 3 ) revealed that SOD activity in the control HR males was by $37.33 \%(p<0.001)$ higher as compared with the LR group, whereas ceruloplasmin content - by $15.90 \%(p<0.001)$ higher, and blood peroxidase activity (BPA) by $18.13 \%(p<0.001)$. These findings evidence the minor lipid peroxidation products content in the LR males as compared with the HR group.

Table 3. Stress-related changes in antioxidant state in heart of HR and LR rats of both sexes, $M \pm m, n=12$

\begin{tabular}{|c|c|c|c|c|}
\hline \multirow[b]{2}{*}{ Group } & \multicolumn{4}{|c|}{ Index } \\
\hline & $\begin{array}{c}\text { SOD } \\
\text { standard unit, } \mathrm{mg}^{-1}\end{array}$ & $\begin{array}{l}\text { Catalase, } \\
\text { mcat } / \mathrm{kg}\end{array}$ & $\begin{array}{c}\text { Ceruloplasmin, } \\
\mathrm{mg} / \mathrm{l}\end{array}$ & $\mathrm{BPA}, \mathrm{mg} / \mathrm{l}$ \\
\hline \multicolumn{5}{|c|}{ Males } \\
\hline \multicolumn{5}{|c|}{$\mathrm{HR}$} \\
\hline Control & $0.98 \pm 0.02$ & $1.61 \pm 0.01$ & $2.35 \pm 0.09$ & $342.90 \pm 1.21$ \\
\hline Stress & $0.19 \pm 0.01$ * & $2.21 \pm 0.04 *$ & $14.85 \pm 0.44 *$ & $788.28 \pm 7.99 *$ \\
\hline \multicolumn{5}{|c|}{ LR } \\
\hline Control & $0.71 \pm 0.01 * *$ & $1.26 \pm 0.06$ & $2.03 \pm 0.05 * *$ & $322.48 \pm 3.38 * *$ \\
\hline Stress & $0.08 \pm 0.02 *, * *$ & $2.58 \pm 0.04 *, * *$ & $13.89 \pm 0.14 * * *$ & $599.71 \pm 6.99 *, * *$ \\
\hline \multicolumn{5}{|c|}{ Females } \\
\hline \multicolumn{5}{|c|}{$\mathrm{HR}$} \\
\hline Control & $0.81 \pm 0.01^{\#}$ & $0.35 \pm 0.03^{\#}$ & $3.63 \pm 0.17^{\#}$ & $283.71 \pm 1.97^{\#}$ \\
\hline Stress & $0.79 \pm 0.02^{\#}$ & $0.88 \pm 0.01$ *,\# & $6.50 \pm 0.07 *$ *\# & $97.43 \pm 2.79 *$,\# \\
\hline \multicolumn{5}{|c|}{ LR } \\
\hline Control & $0.65 \pm 0.01 * *, \#$ & $1.09 \pm 0.01 * *, \#$ & $2.43 \pm 0.06 * *, \#$ & $270.38 \pm 3.76 * *, \#$ \\
\hline Stress & $0.81 \pm 0.02^{*, \#}$ & $0.24 \pm 0.01 *, * *, \#$ & $5.95 \pm 0.05 *, \star *, \#$ & $122.57 \pm 5.42 *, * *, \#$ \\
\hline
\end{tabular}

Notes: * - reliable indices as compared with the controls;

** — reliable indices as compared with the HR;

\# - reliable indices as compared with the males of corresponding group. 
In the males, stress impact caused the decrease in SOD activity (in the HR group - by $80.99 \%, p<0.001$; in the LR group - by $89.22 \%$, $\mathrm{p}<0.001$ ), increase in catalase activity (in the HR group - in 1.38 times, $p<0.001$, in the LR group in 2.04 times, $p<0.001$ ), ceruloplasmin content (in the HR group - in 6.32 times, $p<0.001$, in the LR group - in 6.85 times, $p<0.001$ ), and BPA (in the HR group - in 2.30 times, $p<0.001$, in the LR group - in 1.86 times, $p<0.001)$. In the HR group, SOD activity was by $58.72 \%(p<0.001)$ higher, as well as ceruloplasmin content (by $6.48 \%, p<0.05$ ) and BPA (by 23.92\%, $p<0.001$ ). However, catalase activity was by $16.62 \%$ $(p<0.001)$ lower. The data prove that minor lipid peroxidation products content was provided by higher activity of antioxidant systemic defence in the HR rats.

As against the LR group, the increase in ceruloplasmin content by $25.65 \%(p<0.001)$, the increase in SOD activity by $33.13 \%(p<0.001)$, increase in BPA by $4.70 \%(p<0.01)$ in the control $\mathrm{HR}$ females were revealed, whereas catalase activity decreased in 3.07 times $(p<0.001)$. These findings evidenced the intensive lipid peroxidation process and adequate antioxidant defence in the HR rats. As compared with the females, higher SOD activity (by $16.79 \%, p<0001$ in the HR group and $9.32 \%, p<0.001-$ in the LR group), catalase activity (by $77.95 \%, p<0.001$ in the HR group, by $13.72 \%, p<0.01-$ in the LR group), BPA (by $17.26 \%, p<0.001$ in the HR group and by $16.15 \%, p<0.001$ in the LR group) were found in the intact males. Meanwhile, higher ceruloplasmin content (by $54.56 \%, p<0.001$ in the HR group and by $19.78 \%, p<0.001-$ in the LR group) was evidenced in the females.

In the HR females under stress, catalase activity increased in 2.48 times $(p<0.001)$, ceruloplasmin content - in 1.79 times $(p<0.001)$, whereas BPA decreased by $65.66 \%(p<0.001)$. In the LR females, catalase activity decreased by $78.13 \%(p<0.001)$ and BPA decreased by $54.67 \%(p<0.001)$, while SOD activity increased by $25.38 \%(p<0.001)$ and ceruloplasmin content increased in 2.45 times $(p<0.001)$. As compared with the LR females, higher catalase activity by $72.92 \%(p<0.001)$ and higher ceruloplasmin content by $8.42 \%(p<0.001)$ were revealed in the HR group, while BPA was by $25.81 \%(p<0.001)$ lower. This data indicated that minor lipid peroxidation products content in the HR group was provided by more potent activity of antioxidant system.

In comparison with the males, SOD activity was higher in the females (in 4.27 times, $p<0,001$ and in 10.55 times, $p<0,001$ in the HR and LR groups, respectively). However, higher catalase indices were in the males (by $60.22 \%, p<0.001$ in the HR group and by $90.76 \%, p<0.001$ in the LR group), ceruloplasmin (by $56.26 \%, p<0.001$ in the HR rats and $57.16 \%, p<0.001$ in the LR animals), and BPA (87.64 \%, $<<0.001$ in the HR group and $79.56 \%, p<0.001$ in the LR group. This

Table 4. Stress-related changes in glutathione system in heart of the HR and LR rats of both sexes, $M \pm m, n=12$

\begin{tabular}{|c|c|c|c|}
\hline \multirow[t]{2}{*}{ Group } & \multicolumn{3}{|c|}{ Index } \\
\hline & $\begin{array}{l}\text { Reduced glutathione, } \\
\mathrm{mcmol} / \mathrm{g}\end{array}$ & $\begin{array}{c}\text { Glutathione peroxidase, } \\
\mathrm{mcmol} / \mathrm{min} . \mathrm{kg}\end{array}$ & $\begin{array}{c}\text { Glutathione reductase } \\
\mathrm{mcmol} / \mathrm{min} . \mathrm{kg}\end{array}$ \\
\hline \multicolumn{4}{|c|}{ Males } \\
\hline \multicolumn{4}{|c|}{$\mathrm{HR}$} \\
\hline Control & $776.32 \pm 22.04$ & $0.441 \pm 0.002$ & $0.621 \pm 0.004$ \\
\hline Stress & $1393.27 \pm 40.89 *$ & $0.199 \pm 0.004 *$ & $0.319 \pm 0.001 *$ \\
\hline \multicolumn{4}{|c|}{ LR } \\
\hline Control & $625.73 \pm 25.31$ ** & $0.226 \pm 0.004 * *$ & $0.616 \pm 0.004$ \\
\hline Stress & $1057.02 \pm 12.80 *, * *$ & $0.290 \pm 0.001 *, * *$ & $0.254 \pm 0.001 *, \star \star *$ \\
\hline \multicolumn{4}{|c|}{ Females } \\
\hline \multicolumn{4}{|c|}{ HR } \\
\hline Control & $820.17 \pm 13.68$ & $0.512 \pm 0.001^{\# \#}$ & $0.303 \pm 0.012^{\# \#}$ \\
\hline Stress & $486.84 \pm 24.63^{*, \# \#}$ & $0.132 \pm 0.002 *$ \#\# & $0.155 \pm 0.011^{* \text { *\#\# }}$ \\
\hline \multicolumn{4}{|c|}{ LR } \\
\hline Control & $644.74 \pm 13.68 * *$ & $0.228 \pm 0.003 * *$ & $0.281 \pm 0.004^{\# \#}$ \\
\hline Stress & $451.75 \pm 19.92^{*, \# \#}$ & $0.094 \pm 0.002^{*, * *, \# \#}$ & $0.094 \pm 0.002 *, \star *, \# \#$ \\
\hline
\end{tabular}

Notes: * - reliable indices as compared with the controls;

** — reliable indices as compared with the HR;

\#\# - reliable indices as compared with the males of corresponding group. 
data evidenced minor lipid peroxidation activation due to SOD effect that provided minor accumulation of secondary and final lipid peroxidation products in the females.

During the study of glutathione system indices (Table 4), the reduced glutathione (RG) was revealed by $24.06 \%(p<0.001)$ higher in the HR males as compared with the LR group, glutathione peroxidase values higher by $95.57 \%$ $(p<0.001)$. In the HR females the reduced glutathione values were by $21.39 \%(p<0.001)$ higher and glutathione peroxidase values were by $55.46 \%(p<0.001)$ higher. Enzyme activity was lower in the HR females than in the males (glutathione peroxidase by $16.17 \%, \mathrm{p}<0.001$, glutathione reductase by $51.27 \%, p<0.001$ ), and glutathione reductase in the LR females (by $54.41 \%, p<0.001$ ).

In the males, stress impact caused the increase in reduced glutathione values (the HR group - in 1.79 times, $p<0.001$, the LR group in 1.69 times, $p<0.001)$ and decrease in glutathione reductase activity (the HR group - by $48.62 \%, p<0.001$, the LR group - by $58.80 \%$, $\mathrm{p}<0.001$ ), while glutathione peroxidase values decreased in the HR group by $54.89 \%, p<0.001$ and increased in the LR group by $28.67 \%$, $\mathrm{p}<0.001$.

Stress caused the decrease of reduced glutathione indices (in the HR group - by $40.64 \%$, $p<0.001$, in the LR group - by $29.93 \%, p<0.001$ ), while glutathione reductase activity decreased in the HR group (by $80.26 \%, p<0.001$ ) and increased in the LR group (by $88.39 \%, p<0.001$ ). In the HR group glutathione peroxidase activity remained higher (by $28.79 \%, p<0.001$ ), as compared with the LR group, but glutathione reductase activity was higher (by $39.26 \%$, $\mathrm{p}<0.001)$. All the studied indices in the females under stress impact were lower in comparison with the females (reduced glutathione index in HR group - by $65.06 \%(p<0.001)$, glutathione

\section{References}

1. Rodin R, Bonanno GA, Rahman N, et al. Expressive flexibility in combat veterans with posttraumatic stress disorder and depressionю J. Affect. Disord 2016; 207: 236-241.

2. Crea F, Battipaglia I, Andreotti F. Sex differences in mechanisms, presentation and management of ischaemic heart disease. Atherosclerosis 2015; 241 (1): 157-168. peroxidase - by $66.33 \%(p<0.001)$, and glutathione reductase - by $51.53 \%(p<0.001)$. In the LR group, the indices were $57.26 \%(p<0.001)$, $67.61 \%(p<0.001)$ and $62.96 \%(p<0.001)$, respectively.

Reduced glutathione increase has been noted in the males only; it evidenced of increasing hydroxyl radical which is crucial for the modification of amino acid residues. Besides, in the males the decrease and in the females - increase of SOD-enzyme were revealed that inactivates superoxide-anion radical. Apparently, the processes of free radical oxidation progress differed in the HR and LR rats of both sexes.

\section{Conclusions}

As compared with the LR animals of the same age, minor activity of lipid peroxidation processes owing to TBA-active products were revealed in the intact adult HR male rats, whereas increased activity due to diene conjugates and Schiff bases were evidenced in the female rats. Immobilizing stress causes the development of oxidative and carbonyl stress in the HR and LR rats, more pronounced in the LR group, and the activation of antioxidant defence system. In the males, stress development was concomitant with the increased catalase activity as well as blood peroxidase, ceruloplasmin and reduced glutathione content, whereas the increased catalase and ceruloplasmin activity was evidenced in the HR females, and that of superoxide dismutase and ceruloplasmin - in the LR group, thus failing to provide neutralization of lipid peroxidation products in the latter group. As compared with the females, more intensive oxidative and nitroxidative stress, protein oxidative modification, and stress-related accumulation of circulating immune complexes has been found in the males.

3. Pimple P, Shah AJ, Rooks C, et al. Angina and mental stress-induced myocardial ischemia. J. Psychosom. Res 2015; 78 (5): 433-437.

4. Berezovsky VA. Hypoxia and individual features of reactivity. K.: Naukova Dumka 1978; 216. (In Russian).

5. Kulinskiy VI, Olkhovskiy IA. Two adaptation strategies in adverse conditions: resistant and toler- 
ant. The role of hormones and receptors. Successes of modern biology 1992; 112: 697-711. (In Russian).

6. Khyshiktuyev BS, Khyshiktuyeva NA, Ivanov VN. Methods of determination of lipid peroxidation products in exhaled breath condensate and their clinical significance. Clinical Laboratory Diagnostics 1996; 3: 13-15. (In Russian).

7. Preclinical studies of medication: guidelines; ed. by Corr. Members of AMS of Ukraine A.V. Stefanov. K., Avicenna 2001; 528. (In Ukrainian).

8. Archakov AI, Mikhosoev IM. Modification of proteins by active oxygen and their decomposition. Biochemistry 1998; 54 (2): 179-185. (In Russian).

9. Green IC, Davie AW, Golawski J et al. Analisis of nitrate, nitrite and [15N] nitrate in biological fluids. Anal. biochem 1982; 126 (1): 131-138.

10. Hayevska MYu. Circulating immune complexes in the conditions of norm and pathology. Journal of scientific research 2000; 4: 37-40. (In Ukrainian).

11. Chevari C, Chaba I, Sokey I.The role of superoxide dismutase in cell oxidation process and the method of its determination in biological materials. Lab. bus 1985; 11: 678-681. (In Russian).

12. Koroljuk MA, Ivanova LI, Mayorova IG, Tokarev VE. The method of determining the activity of catalase. Lab. Bus 1988; 1: 16-19. (In Russian).

13. Clinical and laboratory diagnosis. Normative directive legal documents. K: Medinform 2003; 856. (In Ukrainian).

14. PopovT, Neykovska L. Method of determining the peroxidase activity of blood. Hygiene and sanitation 1971; 10: 89-93. (In Russian).

15. Moffat JA, Armstrong PW, Marks GS. Investigations into the role of sulfhydryl groups in the mechanism of action of the nitrates. Canadian Journal of Physiology and Pharmacology 1982; 60 (10): 1261-1266.

16. Kruhlikova HO, Shtutman IM. Glutathione peroxidase and glutathione reductase activity of the liver of rats after introduction of sodium selinate. Ukrainian biochemical journal 1976; 2: 227-233. (In Ukrainian). 